\title{
Videojuegos y aprendizaje colaborativo. Experiencias en torno a la etapa de Educación Primaria
}

\section{Video games and collaborative learning. Experiences related to Primary Education}

\section{Marta Martín del Pozo \\ Facultad de Educación \\ Universidad de Salamanca, España \\ mmdp@usal.es \\ Fecha de recepción: 28-12-2014 \\ Fecha de revisión: 26-03-2015}

Departamento de Didáctica, Organización y Métodos de Investigación.

\section{Palabras clave:}

Videojuego; Aprendizaje colaborativo;

Educación Primaria; Aula.

\section{Resumen}

Los videojuegos no son solamente una forma de entretenimiento, sino que también pueden ser utilizados como recurso educativo para el aprendizaje. En este sentido, el objetivo de este artículo es llevar a cabo una revisión sistemática sobre experiencias e investigaciones del uso de videojuegos en la etapa de Educación Primaria (es decir, con alumnado de 6 a 12 años), pero, de manera particular, experiencias con un enfoque de aprendizaje colaborativo, y también con una evaluación pre y post del aprendizaje que muestre si los alumnos consiguieron ganancias de aprendizaje. Para conseguir dicho objetivo, el artículo está
Fecha de aceptación: 11-05-2015

Fecha de publicación: 15-06-2015

Keywords:

Video games; Collaborative Learning; Primary

Education; Classroom.

\begin{abstract}
Video games are not only a way of entertainment, but also they can be used for learning as an educational resource. In that sense, the aim of this article is to perform a systematic review about experiences and research about the use of video games in the stage of Primary Education (that is to say, with children between 6 and 12 years old), but, in particularly, experiences with a collaborative learning approach and, also, with a pre and post achievement or learning test to show if students made learning gains. In order to fulfill the main objective, the article will be divided in five key sections showing the main aspects related to this
\end{abstract}


dividido en cinco secciones que muestran los principales aspectos relacionados con este tema: videojuegos en educación, aprendizaje colaborativo, la metodología para la revisión sistemática, resultados y conclusiones. Como resultado, 8 estudios cumplían los criterios de inclusión y fueron seleccionados para el análisis. En este sentido, mostramos que los videojuegos pueden ser utilizados bajo un enfoque de aprendizaje-trabajo colaborativo, en contraste a la idea extendida de que los videojuegos generan personas aisladas, sobre todo en el caso de los menores y, además, en general, los alumnos consiguen mejoras en su aprendizaje. En conclusión, los videojuegos pueden ser un buen recurso para el proceso de aprendizaje y, por ejemplo, pueden ser utilizados dentro de un enfoque de aprendizaje colaborativo pero es necesaria más información sobre esto debido a los límites que mostramos al final del artículo, como, por ejemplo, la necesidad de más estudios con evaluación pre y post de los logros de aprendizaje y que usen grupos de control y experimental.

\section{Introducción}

Los videojuegos se sitúan como uno de los recursos más utilizados como elemento de entretenimiento, estando omnipresentes en nuestras vidas. ¿Quién no ha visto a personas o jugado a videojuegos esperando para un evento o en el transporte público? En este sentido, los videojuegos llaman la atención topic: video games in education, collaborative learning, the methodology for the systematic review, results and conclusions about the results. As a result, a total of 8 studies met the inclusion criteria and they were selected for the analysis. In that sense, we show that video games can be used in a collaborative learning approach, in contrast to the common idea that video games generate isolate persons, above all children and, furthermore, in general, students improve their learning achievement. In conclusion, video games can be a good resource for learning process and, for example, they can be used in a collaborative learning approach but it is necessary more information about that because of the limits we show at the end of the article, like, for example, more studies are required with pre and post achievement tests and using experimental and control groups.

de nuestros estudiantes en el día a día, que se encuentran inmersos en estos mundos digitales, motivándoles a persistir, seguir insistiendo, para lograr los objetivos, ya sea llegar a la meta, conseguir elementos o salvar a otro personaje. Los jugadores insisten, vuelven a intentarlo, cambian la estrategia si 
fallan, replantean la hipótesis, colaboran con otros personajes o jugadores, todo ello con ánimo, interés y ganas de lograr los objetivos. Dicho lo cual nos podemos plantear ¿por qué no utilizarlo como recurso educativo? De hecho, estos aspectos mencionados deberían ser igualmente aplicables en la educación, como que los estudiantes insistieran en sus aprendizajes, volvieran a intentarlo, replantearan las estrategias de aprendizaje y las hipótesis si no funcionaran, colaboraran con otros estudiantes, todo ello con ánimo e interés de lograr el aprendizaje.

En este sentido, en este texto trabajamos sobre el aprendizaje colaborativo con videojuegos, como un enfoque a tener en cuenta que aglutina los beneficios del aprendizaje colaborativo y de los videojuegos, implicando a los estudiantes en tareas con un elemento

\section{Videojuegos y Educación}

Visto que los videojuegos son un elemento de ocio muy extendido en la sociedad, ¿por qué no utilizarlo como recurso educativo?

Numerosos estudios y autores han señalado aspectos positivos y beneficios en términos de aprendizaje de los videojuegos (Etxeberría, 1998; Gros, 2000; Gee, 2004; Felicia, 2009; Marquès, 2011; AEVI \& GfK, 2012a, 2012b; Revuelta y Guerra, 2012, entre otros) desde diferentes perspectivas. Mencionamos, por ejemplo, el desarrollo de habilidades y destrezas, el trabajo de contenidos (incluyendo contenidos curriculares) y actitudes (solidaridad, respeto o tolerancia) y que procede de su experiencia fuera del aula y trabajando de manera colaborativa, praxis muy reclamada en una sociedad cada vez más diversa.

Para ello, presentamos primero dos apartados a modo de estado de la cuestión relativos a videojuegos en educación y al aprendizaje colaborativo ya sea con o sin tecnologías. A continuación, presentamos la metodología de nuestro estudio, pues tratará de una revisión sistemática en torno a experiencias y estudios en la etapa de Educación Primaria en las que se haya utilizado un videojuego en torno al cual se hayan realizado actividades colaborativas ya sea dentro del juego o fuera de él. Después, presentamos los resultados encontrados para posteriormente pasar a un proceso de discusión de dichos resultados.

el aumento de la autoestima y la motivación. Además, como muestra de su beneficio educativo, podemos encontrar experiencias de aula en las cuales se utilizaron videojuegos o propuestas y análisis indicando qué cuestiones se podrían trabajar. Presentamos entonces algunos ejemplos relativos a la etapa de Educación Primaria (en términos de edad relativos al sistema educativo español, es decir, entre 6 y 12 años) por ser en la que centramos el análisis posterior.

En cuanto a experiencias de utilización en el aula, Bottino, Ferlino, Ott y Tavella (2007) presentan un proyecto para promover las 
habilidades estratégicas y de razonamiento en alumnos de primaria al utilizar videojuegos de ordenador, principalmente "mind games" o juegos mentales (por ejemplo, PappaLOTTO, Hexip, Studio 5, Magical Balls y Math Blaster). García Gigante (2009) utiliza el videojuego Pokémon Diamante (2007) en $4^{\mathrm{O}}$ de Educación Primaria para desarrollar la competencia para trabajar con tablas alfanuméricas y gráficos de barras. Lacasa (2011) presenta un taller en Educación Primaria en el que trabajaron el fenómeno trans-media de Harry Potter para contribuir al desarrollo del pensamiento narrativo, usando Harry Potter y el Cáliz de Fuego en formato película (2005), videojuego (2005) y otros objetos. Por otro lado, Macías y Quintero (2011) presentan una investigación en la que se exploraba el uso de ambientes virtuales de videojuegos comerciales para el desarrollo de la orientación espacial con alumnado de quinto y sexto y los videojuegos Fable (2004) y Sacred (2004). García y Raposo (2013) presentan una experiencia con alumnado de tercer ciclo trabajando la percepción y discriminación auditiva con Wii Music (2008) y el programa Earmaster. Por último, Artola (2014) nos muestra varias experiencias, en una de las cuales se aplicó God of War (2005) para la enseñanza y aprendizaje de elementos mitológicos en narrativas digitales con alumnado de 11 y 12 años.

En lo que respecta a propuestas o análisis de videojuegos en relación a los aspectos educativos que se podrían trabajar, el Grupo F9 realiza análisis de multitud de juegos, como el videojuego Snoopy (Grupo F9, 2002), con el que se plantea trabajar con niños de 6 a 8 años el desarrollo de habilidades de comprensión lectora y se pueden trabajar contenidos de áreas como Ciencias Sociales y Matemáticas. Por otro lado, Haunted House podría utilizarse con alumnado de $5^{\mathrm{o}}$ y $6^{\mathrm{o}}$ de Primaria en inglés en fechas cercanas a Halloween para familiarizarse con el vocabulario y aprender a dirigir y entender a otra persona en otro idioma (Santamaría y Grupo F9, 2007).

Marín, Ramírez y Cabero (2010) realizan una propuesta de empleo de un videojuego de la saga Lemmings en quinto de Educación Primaria con un enfoque basado en competencias básicas. Por otro lado, Arias y Revuelta (2014) analizan videojuegos y elaboran una propuesta de secuencia didáctica de cómo llevarlos al aula, como con New Super Mario Bros. (2006), alrededor del cual se plantean actividades para el tercer ciclo respondiendo al objetivo curricular relativo a desarrollar hábitos de trabajo individual y de equipo respetando a todos los alumnos. También Guerra y Revuelta (2014) proponen diferentes actividades con Minecraft (2009) planteadas para $2^{\mathrm{O}}$ y $3^{\mathrm{O}}$ ciclo, trabajando, entre otras, el fomento de actitudes de cooperación y comunicación entre iguales e intergrupos, nociones de cálculo o asignación de tareas.

Como vemos, los videojuegos pueden utilizarse en Educación Primaria para el aprendizaje de conceptos, habilidades y actitudes, y en relación a diferentes áreas, 
como Matemáticas, Lengua y Música. aprendizaje colaborativo, praxis necesaria en Pero, ¿y por qué no plantearlo a través del esta sociedad cada vez más diversa?

\section{Aprendizaje Colaborativo}

Si buscamos en el diccionario de la Real Academia Española (RAE) el término "colaborar" entre sus acepciones está: "Trabajar con otra u otras personas en la realización de una obra" (RAE, 2001). Sin embargo, para adentrarnos en el término "aprendizaje colaborativo" y conocer las nociones subyacentes necesitamos ir más allá y focalizarnos en lo que señalan autores al respecto.

En cuanto a definiciones del aprendizaje colaborativo Barkley, Cross y Major (2007) indican que

$$
\begin{aligned}
& \text { "el aprendizaje colaborativo es una actividad } \\
& \text { estructurada de aprendizaje que aborda las } \\
& \text { principales preocupaciones relacionadas con la } \\
& \text { mejora en la forma de aprender de los alumnos. } \\
& \text { Implica activamente a los estudiantes, poniendo } \\
& \text { así en práctica la conclusión predominante de } \\
& \text { medio siglo de investigación sobre el desarrollo } \\
& \text { cognitivo. Los preparan para sus carreras } \\
& \text { profesionales, dándoles la oportunidad de } \\
& \text { aprenderlascompetencias detrabajoen grupo que } \\
& \text { valoran los empresarios. Ayuda a los estudiantes } \\
& \text { a apreciar múltiples perspectivas y a desarrollar } \\
& \text { competencias para abordar colaborativamente } \\
& \text { los problemas comunes de cara a una sociedad } \\
& \text { diversa; y compromete a todos los alumnos } \\
& \text { valorando la perspectiva que cada uno puede } \\
& \text { aportar desde su experiencia personal académica }
\end{aligned}
$$

y vital. Dicho esto, el aprendizaje colaborativo es un método apropiado para conseguir algunos objetivos y realizar ciertas tareas, pero no para otros. En la mayoría de los casos, consideramos que el aprendizaje colaborativo no es un sustituto de la clase magistral, el diálogo u otros métodos tradicionales, sino un complemento útil"

(Barkley et al., 2007, p. 21).

Por otra parte, Iborra e Izquierdo (2010) señalan que el aprendizaje colaborativo es

"un tipo de metodología docente activa, que se incluye dentro del enfoque del constructivismo del aprendizaje, en la que cada alumno construye su propio conocimiento y elabora sus contenidos desde la interacción que se produce en el aula. En un grupo colaborativo existe, pues, una autoridad compartida y una aceptación por parte de los miembros del grupo de la responsabilidad de las acciones y decisiones del grupo. Cada miembro del equipo es responsable total de su propio aprendizaje y, a la vez, de los restantes miembros del grupo"

(Iborra e Izquierdo, 2010, p. 223).

Como vemos, podemos resaltar varias ideas fundamentales de lo que mencionan. Por un lado, la interacción, implicación activa y compromiso de todas las personas. Por otro, la autoridad y responsabilidad compartida de todos los participantes del aprendizaje colaborativo tanto en las decisiones y 
acciones como en el aprendizaje propio y del resto, llevando de esta manera al abordaje colaborativo de los problemas y la valoración de la perspectiva y experiencia de cada uno como riqueza vital y académica de los integrantes. Además, como enfoque en el aula es necesario que se lleve a cabo a través de un proceso o actividad estructurada.

Este tipo de metodologías, según lo recogido por Calzadilla (2002), Scagnoli (2006), Carrió (2007) y Barkley et al. (2007), conllevan ventajas y beneficios en torno a: un aprendizaje significativo, duradero y más profundo en términos conceptuales, de habilidades, actitudinal y competencial; mayor motivación en cuanto a la realización de tareas; mejora de autoestima, satisfacción personal y confianza en sí mismo; conocimiento de su propio ritmo y estilo de aprendizaje; y desarrollo y fomento de situaciones que llevan a la amistad personal y profesional.

Teniendo en cuenta esto podemos reseñar experiencias englobadas bajo el paraguas del aprendizaje/trabajo colaborativo, también con alumnado de Primaria, que nos permiten ver, en términos de práctica de aula, la bondad del trabajo colaborativo en contextos de aprendizaje de distinta naturaleza, ya sea con tecnologías o sin ellas.

Garibay et al. (2008) presentan una investigación sobre el trabajo colaborativo entre niños de $6^{\mathrm{o}}$ grado de primaria mediante la utilización de foros de discusión en línea. El desempeño del alumnado en el trabajo colaborativo realizado a distancia fue satisfactorio y la aceptación y agrado por esta metodología fue muy bueno.

Por su parte, Renou y Lozano (2010) muestran una experiencia para mejorar la competencia lingüística en castellano de 6 discentes marroquíes de $3^{\mathrm{o}}, 4^{\mathrm{o}}$ y $5^{\mathrm{o}}$ de Primaria mediante el trabajo colaborativo. Se quería fomentar la interacción lingüística, mejorando sus destrezas comunicativas y favorecer y practicar la ayuda mutua y transmitir valores humanistas. Los discentes mejoraron en lengua castellana, a la par que se promovieron las alianzas y el sentido de pertenencia a un grupo a través del desarrollo de actitudes de ayuda mutua y habilidades sociales.

Además, podemos resaltar los resultados obtenidos por García-Valcárcel y Basilotta (2015) al evaluar un proceso de aprendizaje desarrollado a través de la participación de alumnado de Primaria en proyectos de aprendizaje colaborativo con TIC. A través de la aplicación de una escala de evaluación con formato de diferencial semántico a 140 alumnos se obtuvo que vivieron de forma satisfactoria la experiencia de los proyectos, valorando de manera positiva el proceso y los resultados, mostrándose satisfechos con el aprendizaje. A su vez, podemos recalcar los resultados obtenidos por Pedrero, Sánchez e Iglesias (2014) en cuanto a las percepciones positivas de docentes de Primaria sobre los procesos curriculares de aprendizaje colaborativo con el uso de TIC.

En este sentido, vemos que a través de tecnologías también se pueden realizar actividades de aprendizaje colaborativo, 
pero ¿qué ocurre con los videojuegos? Entonces, ¿podrían plantearse actividades Felicia señala que (2009, pp. 7-8) "la de aprendizaje colaborativo en las que el premisa de los videojuegos es aprender, recurso principal sea un videojuego y las memorizar, colaborar, explorar o conseguir tareas colaborativas giren en torno a él ya información suplementaria para avanzar". sea dentro o fuera del videojuego?

\section{Metodología}

Llevaremos a cabo una revisión sistemática de las contribuciones de investigación, experiencias e innovaciones de aula que se enmarcan dentro de lo que denominamos aprendizaje colaborativo con videojuegos, es decir, situaciones de aprendizaje/trabajo colaborativo en las que el videojuego es el recurso principal en torno al que se trabaja de manera colaborativa, ya sea dentro de él o fuera de él a partir de lo jugado en él. Como señala Sánchez-Meca (2010), una revisión sistemática se trata de un tipo de investigación científica mediante la cual los investigadores han de revisar la literatura científica generada en torno a un tema, partiendo de una pregunta de investigación formulada de forma precisa que permita guiar el proceso, utilizando en la búsqueda de la información métodos sistemáticos y explícitos que les permitan localizar, seleccionar y valorar de manera crítica las investigaciones relevantes relativas a dicha cuestión y aplicando protocolos sistemáticos para dicha recogida de datos e información de las investigaciones, todo ello con el fin de llegar a conclusiones válidas y objetivas sobre qué es lo que muestran las evidencias sobre el tema en cuestión. Para dicho proceso, vamos a tener en cuenta las consideraciones realizadas por Sánchez-Meca (2010) y los pasos señalados por Boland, Cherry y Dickson (2014) para realizar una revisión sistemática.

Como partes fundamentales de dicho proceso es preciso que planteemos de manera clara nuestra pregunta para la revisión, de la cual se extraen los objetivos que queremos alcanzar, a la par que la definición de los criterios de demarcación de la búsqueda o de inclusión y exclusión de los estudios.

Como pregunta nos planteamos la siguiente: ¿Pueden plantearse en la etapa de Educación Primaria, es decir, con alumnado de entre 6 y 12 años, actividades de trabajo colaborativo entre los propios alumnos en las que el recurso principal en torno al que se desarrolla la actividad sea un videojuego, ya sea colaborando dentro del videojuego o fuera de él? En base a ella, los objetivos son: Conocer si se han realizado actividades de aprendizaje colaborativo con videojuegos con alumnado de entre 6 y 12 años; Conocer si han mejorado los resultados de aprendizaje del alumnado participante en dicho planteamiento de aula. A la hora de la selección de los estudios se 
han tenido en cuenta los siguientes criterios de aula, Metodología de investigación y de demarcación de la búsqueda, clasificándose Características del texto, que aparecen en la en las categorías Alumnado, Metodología Tabla 1.

\begin{tabular}{|c|c|}
\hline \multirow[t]{2}{*}{ Alumnado } & $\begin{array}{l}\text { Solamente se aceptarán estudios con alumnado de entre } 6 \text { y } 12 \\
\text { años, edades relativas a la etapa de Educación Primaria en } \\
\text { España. }\end{array}$ \\
\hline & $\begin{array}{l}\text { No se aceptarán estudios con alumnado con altas capacidades o } \\
\text { con necesidades educativas específicas. }\end{array}$ \\
\hline Tipo de videojuego & $\begin{array}{l}\text { Se aceptarán estudios de prácticas de aula con videojuegos } \\
\text { tanto Serious Games como Games for Entertainment (Meyer y } \\
\text { Sørensen, 2009). }\end{array}$ \\
\hline \multirow[t]{3}{*}{ Metodología de aula } & $\begin{array}{l}\text { Solamente se aceptarán intervenciones de aula en las que se } \\
\text { utilicen videojuegos como recurso en metodologías de } \\
\text { aprendizaje colaborativo, ya sea la colaboración dentro del } \\
\text { videojuego o fuera. No se aceptarán estudios en los que las } \\
\text { prácticas sean individuales. }\end{array}$ \\
\hline & $\begin{array}{l}\text { No se aceptarán estudios en los que el alumnado tenga que } \\
\text { crear videojuegos o juegos digitales. Se aceptarán solamente } \\
\text { aquellas prácticas donde se utilicen juegos ya creados. }\end{array}$ \\
\hline & $\begin{array}{l}\text { No se aceptarán estudios en los que solamente se utilicen } \\
\text { elementos contextuales de los videojuegos como parte separada } \\
\text { (carátulas, figuras o imágenes de personajes). Es necesario que } \\
\text { los alumnos jueguen con los videojuegos. }\end{array}$ \\
\hline $\begin{array}{l}\text { Metodología } \\
\text { investigación }\end{array}$ & $\begin{array}{l}\text { Solo se aceptarán estudios en los que haya existido una } \\
\text { evaluación pre-test y post-test en cuanto a resultados de } \\
\text { aprendizaje. }\end{array}$ \\
\hline
\end{tabular}




\begin{tabular}{|c|c|}
\hline \multirow{5}{*}{$\begin{array}{l}\text { Características del } \\
\text { texto }\end{array}$} & Se aceptarán estudios en español e inglés. \\
\hline & Se aceptarán estudios procedentes de cualquier país. \\
\hline & $\begin{array}{l}\text { Se aceptarán artículos, comunicaciones, presentaciones en } \\
\text { congresos y libros. }\end{array}$ \\
\hline & $\begin{array}{l}\text { Se aceptarán textos disponibles en diversas bases de datos o } \\
\text { portales: Dialnet (http://dialnet.unirioja.es/), ERIC } \\
\text { (http://eric.ed.gov/) } \\
\text { (http://www.sciencedirect.com/). }\end{array}$ \\
\hline & $\begin{array}{l}\text { Se revisarán las referencias de los textos que cumplan con los } \\
\text { criterios para la localización de mayor número de textos. }\end{array}$ \\
\hline
\end{tabular}

\section{Resultados. Experiencias De Aprendizaje Colaborativo Con Videojuegos}

En base a los criterios de demarcación señalados para la búsqueda, tuvimos que excluir estudios que no respondían a los criterios, sobre todo porque no incorporaban una prueba pre-test y post-test que nos permitiera conocer las diferencias en resultados de aprendizaje, a la par que estudios con alumnado de otras edades.

De este modo, se incluyeron 8 estudios (Tabla

2) comprendidos cronológicamente entre 2000 (Henderson, Klemes y Eshet, 2000) y 2014 (Lester et al., 2014). En cuanto a la muestra de alumnado, las edades comprenden el rango establecido de 6 a 12 años y se presenta diversidad en el tamaño de la muestra, desde 8 alumnos (Lim, Nonis y Hedberg, 2006) hasta más de 200 (Lester et al., 2014). A su vez, proceden de diferentes países, Estados Unidos (tres de ellos), Singapur, Italia, Turquía, Suecia y Taiwán. En cuanto al videojuego, todos ellos utilizan un Serious Game y en 6 ocasiones disponemos del nombre.

En lo que respecta al proceso llevado a cabo, difiere la temporalización de las actividades a realizar en torno al juego, siendo en algún caso 3 horas como ocurre en Tüzun, YilmazSoylu, Karakus, Inal y Kizilkaya (2009) en el que utilizaron el videojuego durante 3 semanas, una hora al día una vez por semana, mientras que, por otro lado, en Garzotto 
(2007) se realizaron 4 sesiones, cada una de una duración aproximada de 115 minutos. En este sentido, el número de alumnos en las agrupaciones giró en torno a pequeños grupos de entre 2 y 4 alumnos, siendo la agrupación en forma de pareja la más recurrente, aunque también, como vemos en Garzotto (2007), el alumnado estaba organizado en dos equipos y cada equipo (con un objetivo común para colaborar) estaba subdividido en 4 grupos de 2 o 3 niños que participaban en un ordenador representando a un jugador.

En relación a diferentes elementos metodológicos de los estudios, todos los estudios realizan algún tipo de prueba pretest y post-test en términos de ganancias de aprendizaje, cumpliendo nuestro criterio de inclusión. A su vez, 5 de ellos realizan el estudio de varias formas de trabajo (grupos experimentales y/o control), permitiendo establecer si hubo diferencias en dichas formas de trabajo. En Henderson et al. (2000) se compararon 3 parejas seleccionadas que trabajaban juntas durante el tiempo de investigación con el resto de alumnos que mayormente trabajaron con compañeros, pero dependiendo de cómo se sentían o la disponibilidad de compañero elegían trabajar con otro $\mathrm{u}$ ocasionalmente solos, teniendo en cuenta entonces el hecho de interacciones entre compañeros más permanentes o menos durante el juego. En cuanto a Meluso, Sheng, Spires y Lester (2012) se comparó la condición de juego de jugador único o la condición colaborativa en cuanto a participación en el juego. Pareto, Haake, Lindström, Sjöden y Gulz (2012) comparan el juego en parejas en una clase mientras que en otra se sigue el currículum ordinario. En Sung y Hang (2013) se comparó un grupo experimental que aprendía con el videojuego colaborativo de ordenador acompañado de una tabla compartida, un grupo control A que aprendía con el videojuego de manera colaborativa pero sin usar la tabla, y un grupo de control B que aprendía individualmente y desarrollaban sus propias tablas. Por último, Lester et al. (2014) compararon utilizar el juego de manera colaborativa entre dos alumnos cara a cara y, por otro, utilizando el videojuego de manera colaborativa entre dos alumnos de forma virtual, en ambos casos con enfoque "planner-driver".

Por último, en cuanto a los resultados, podemos hablar, en términos generales, de que los estudios muestran en los post-test un incremento del aprendizaje de los alumnos por participar en la actividad con el videojuego de manera colaborativa. 


\begin{tabular}{|c|c|}
\hline 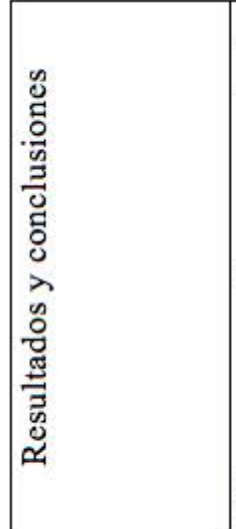 & 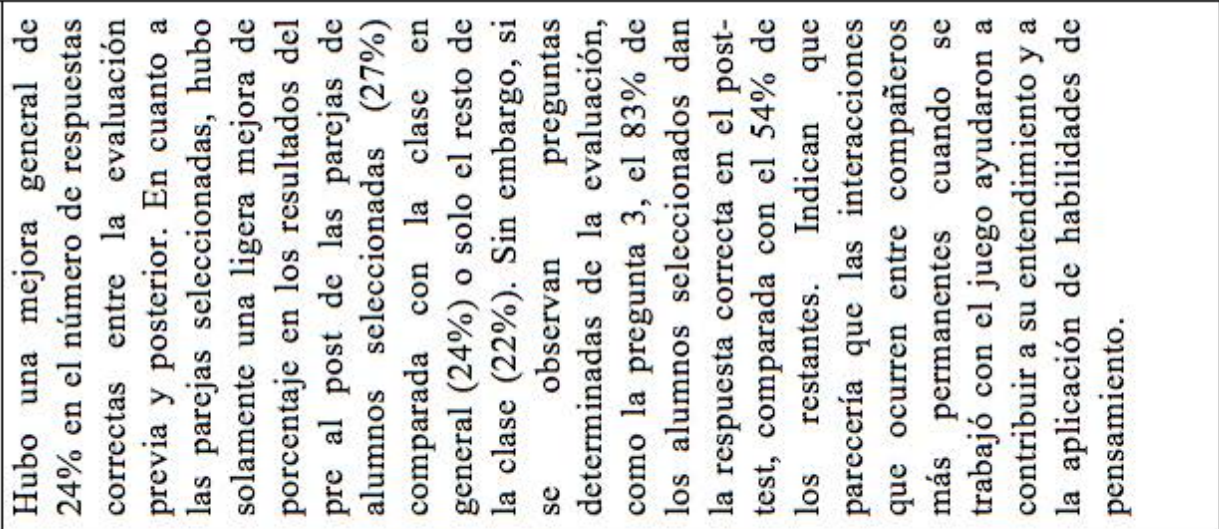 \\
\hline 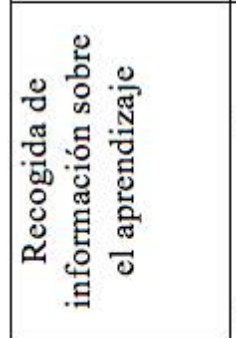 & 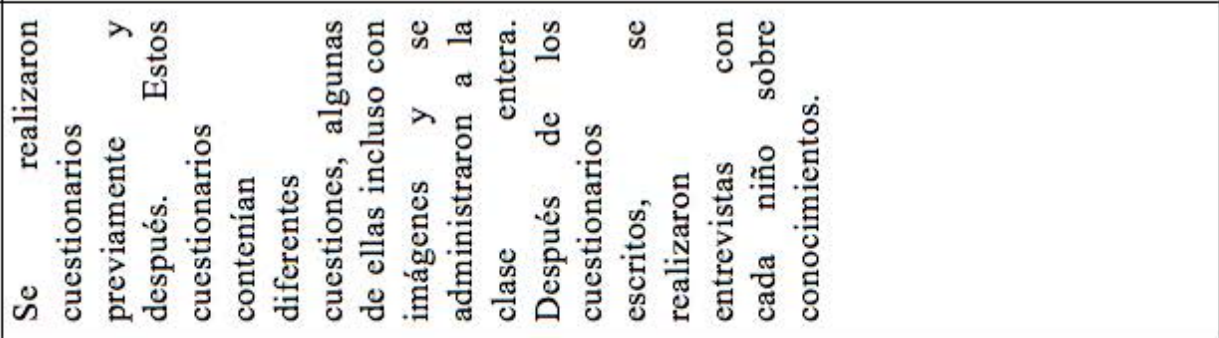 \\
\hline 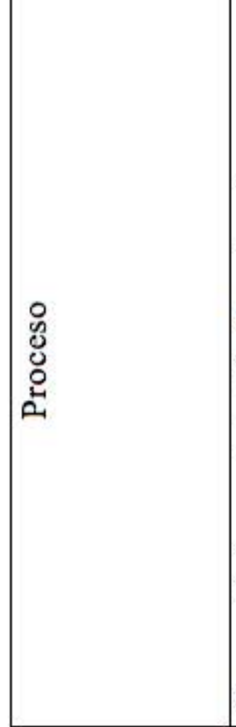 & 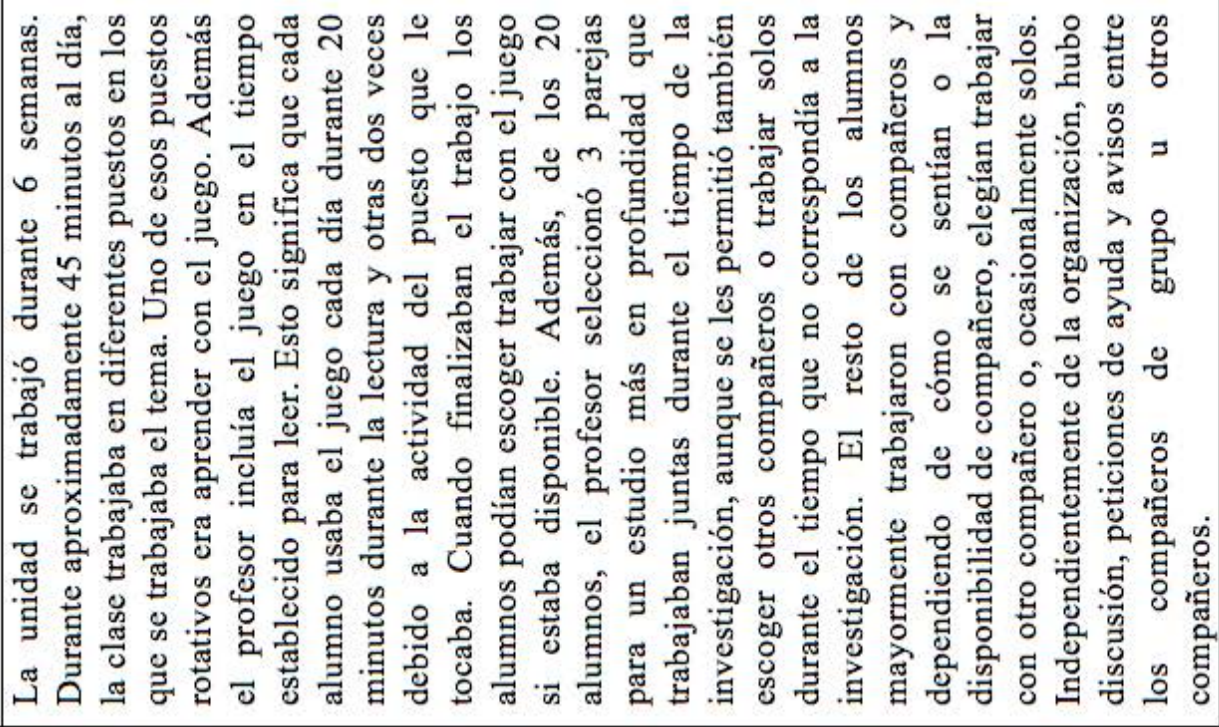 \\
\hline 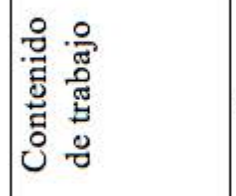 & 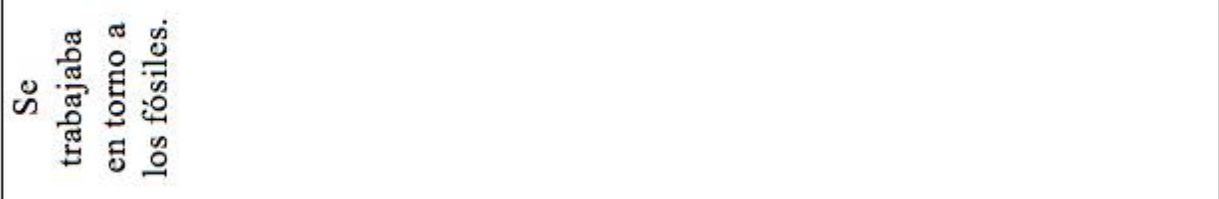 \\
\hline 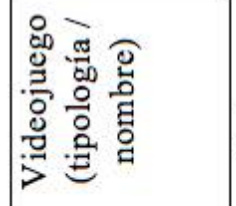 & 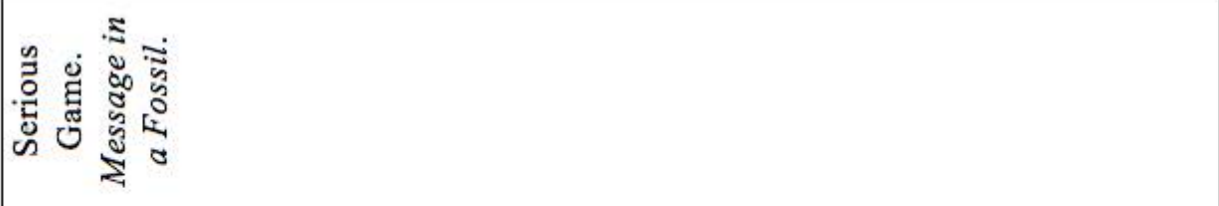 \\
\hline 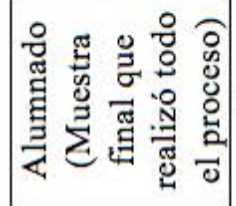 & 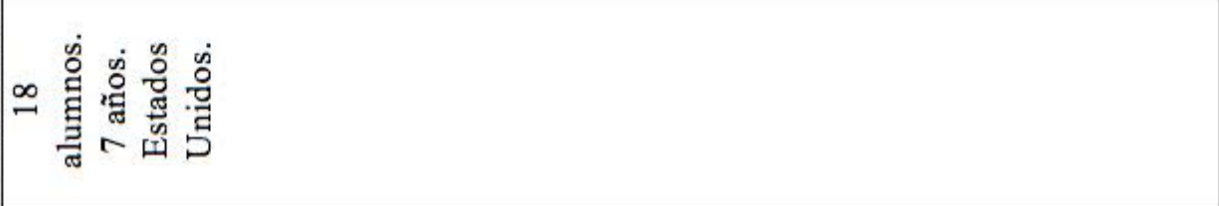 \\
\hline & 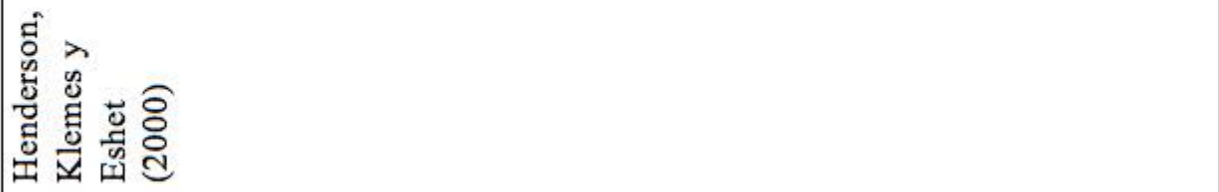 \\
\hline
\end{tabular}




\begin{tabular}{|c|c|c|}
\hline 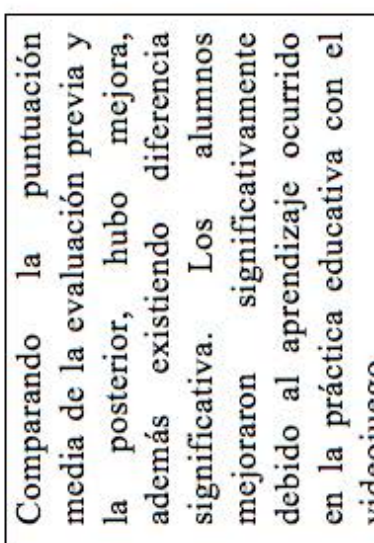 & 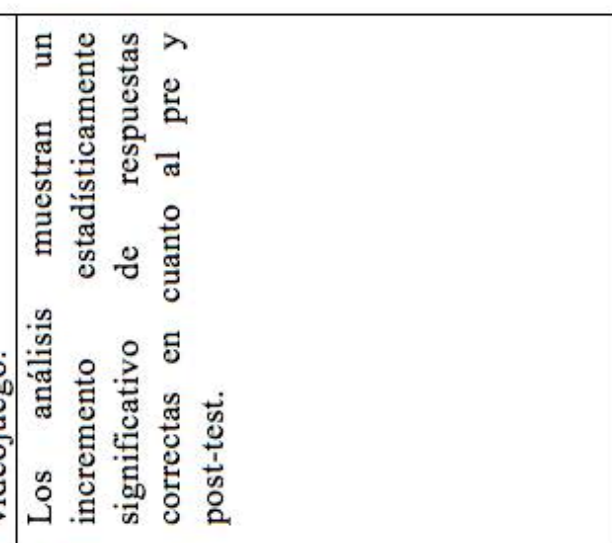 & 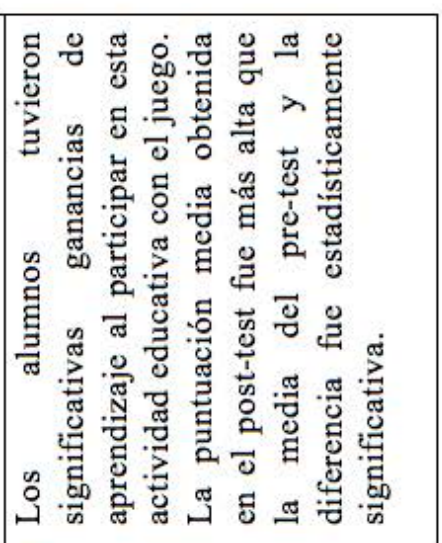 \\
\hline 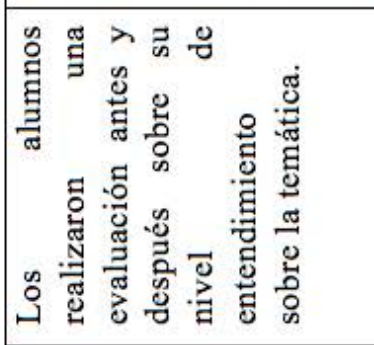 & 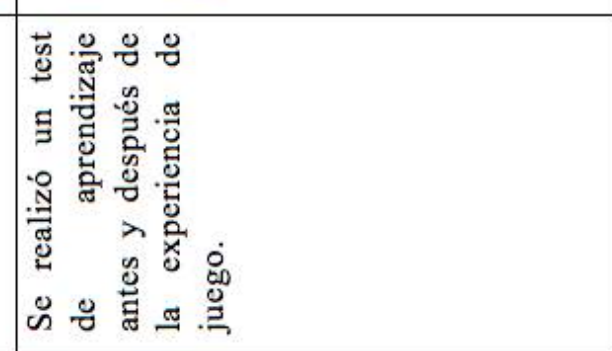 & 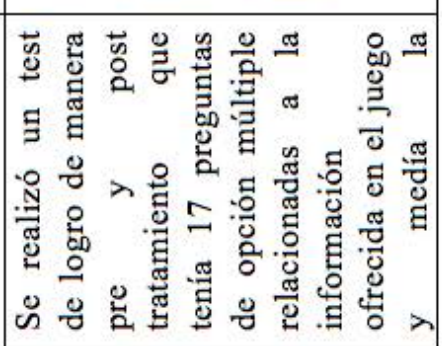 \\
\hline 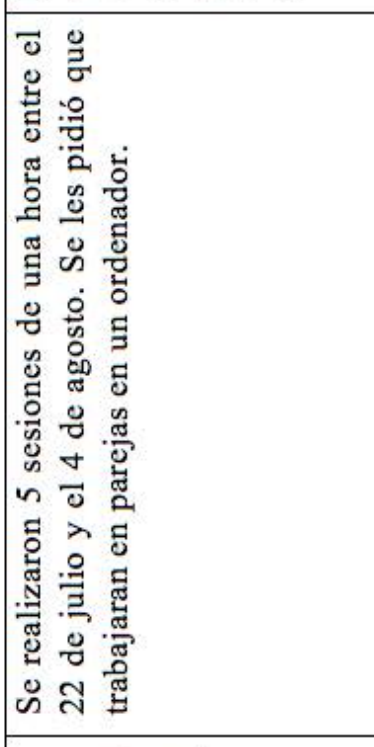 & 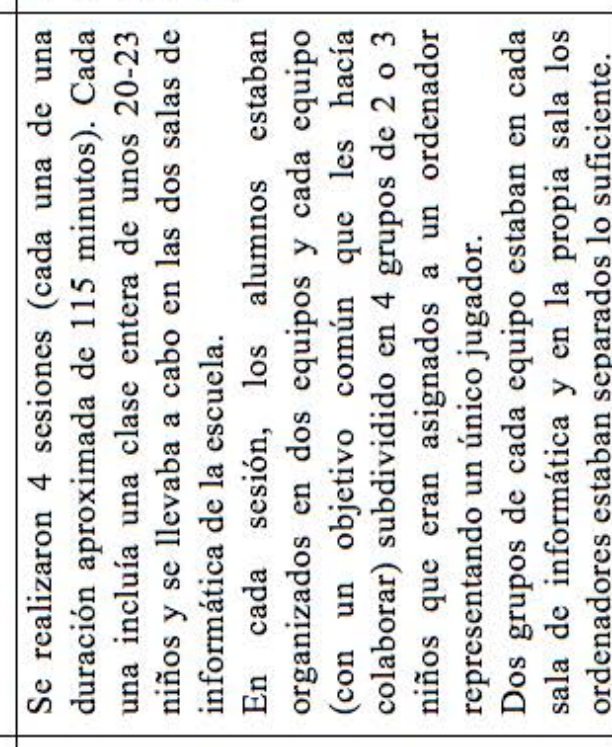 & 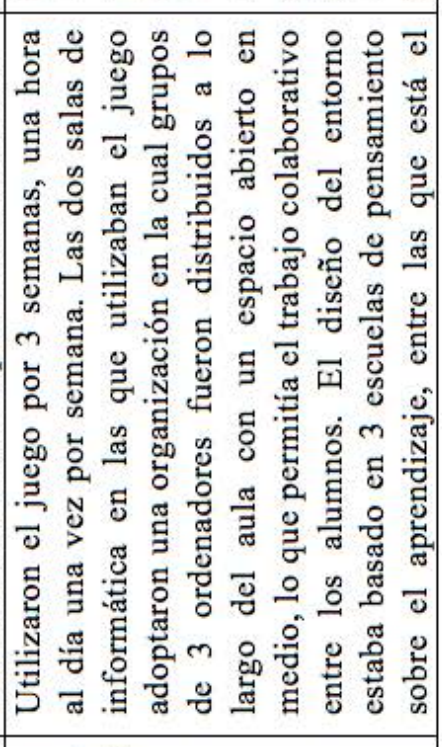 \\
\hline 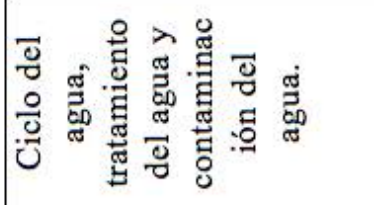 & 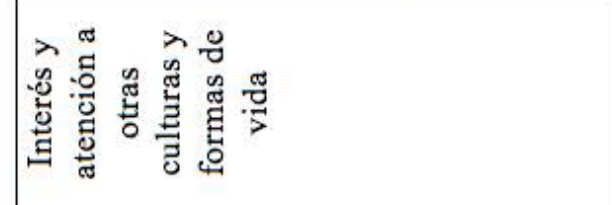 & 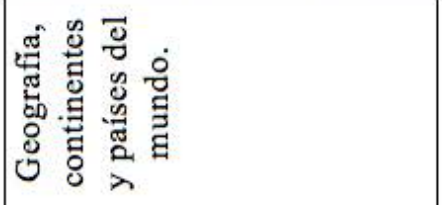 \\
\hline 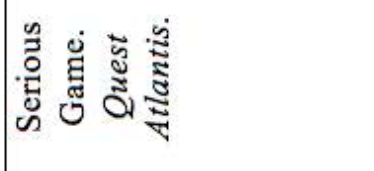 & 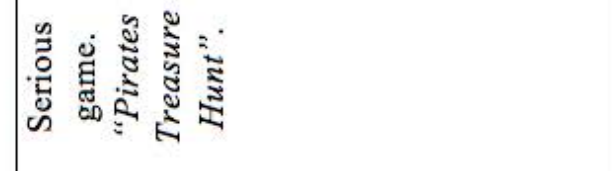 & 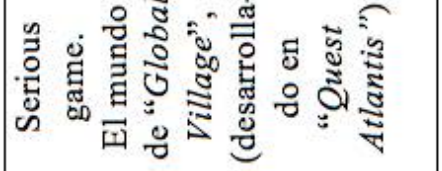 \\
\hline 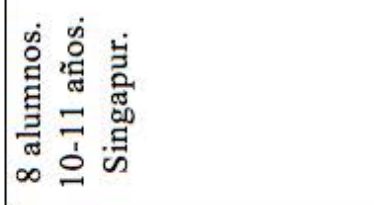 & 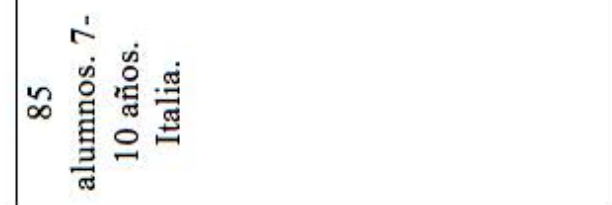 & 列 \\
\hline 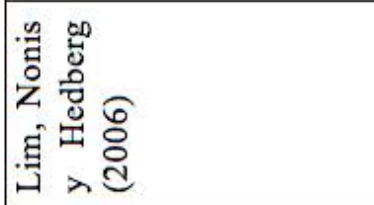 & (1) & 辞 \\
\hline
\end{tabular}




\begin{tabular}{|c|c|c|}
\hline & 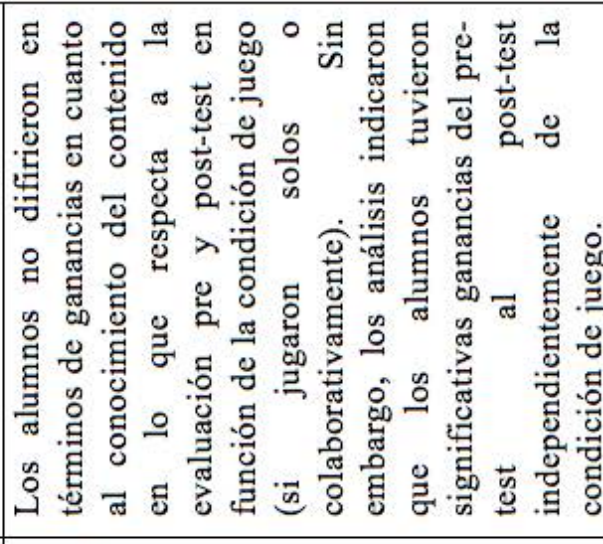 & 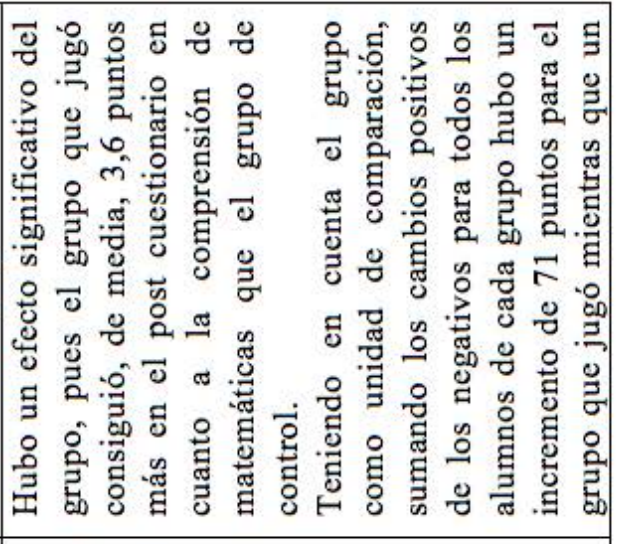 \\
\hline 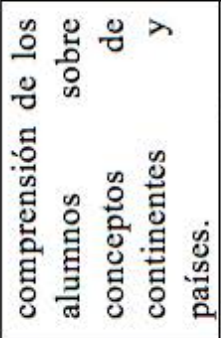 & 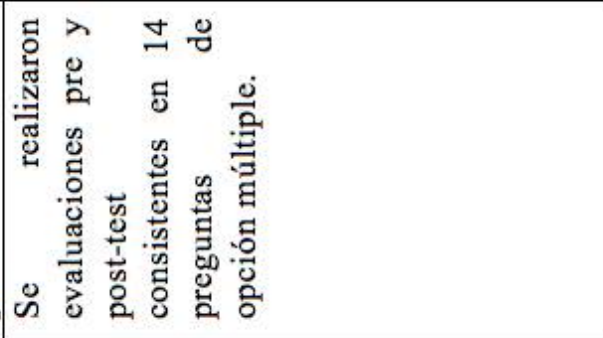 & 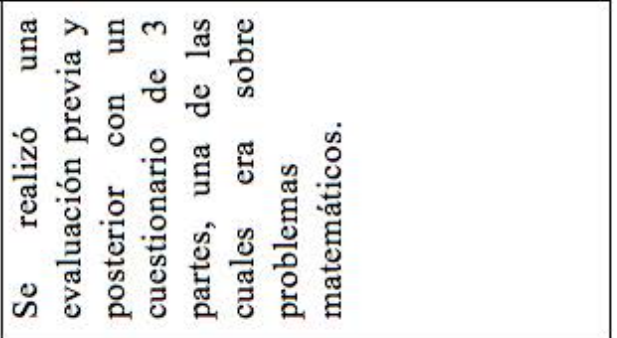 \\
\hline \multirow[t]{5}{*}{ 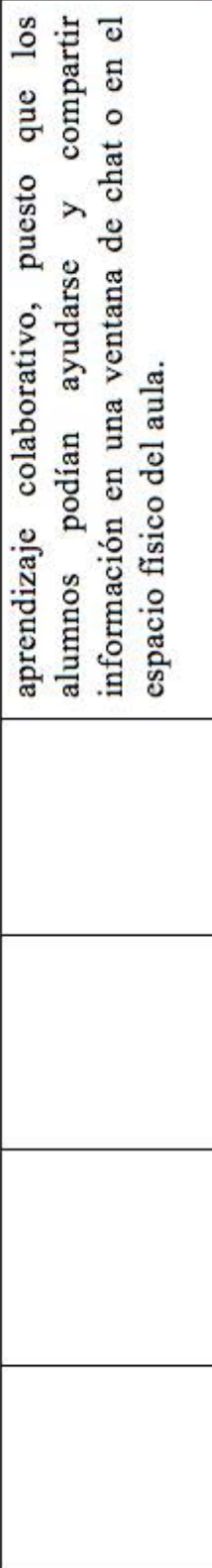 } & 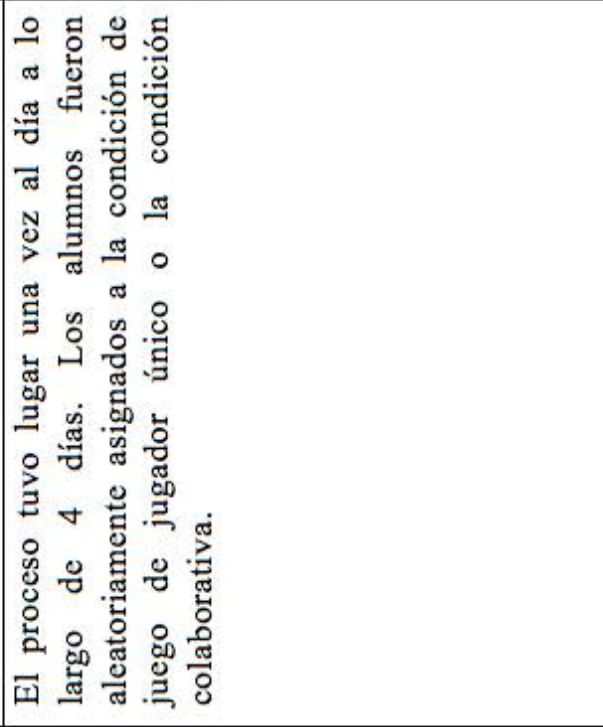 & 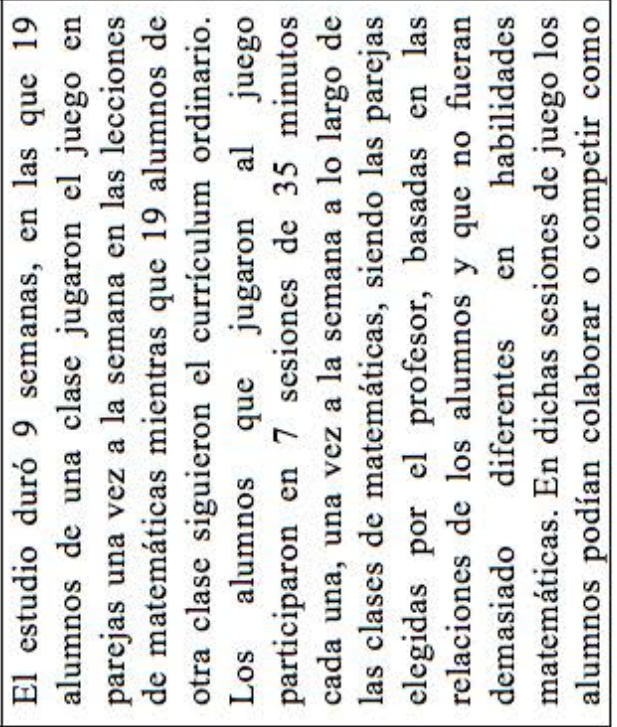 \\
\hline & 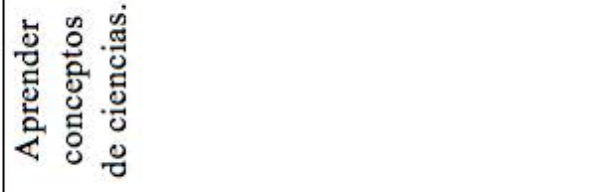 & . \\
\hline & 章芯芯 & 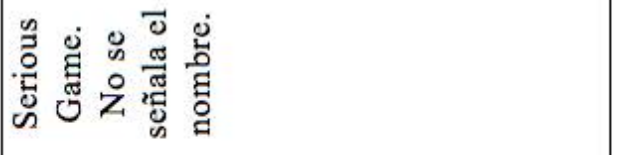 \\
\hline & 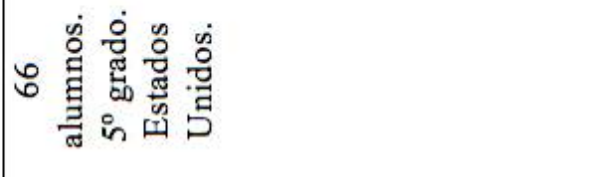 & 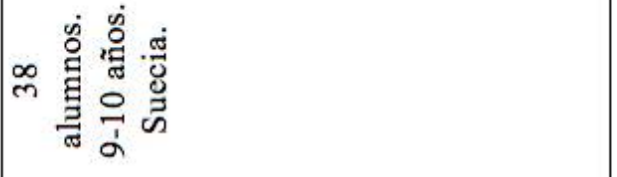 \\
\hline & 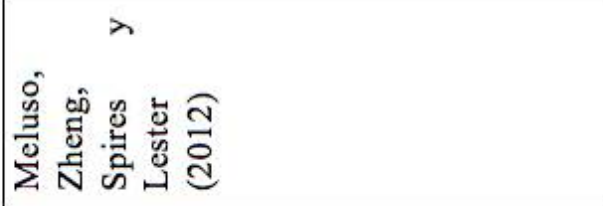 & 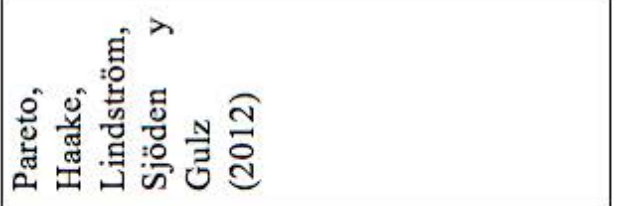 \\
\hline
\end{tabular}




\begin{tabular}{|c|c|}
\hline 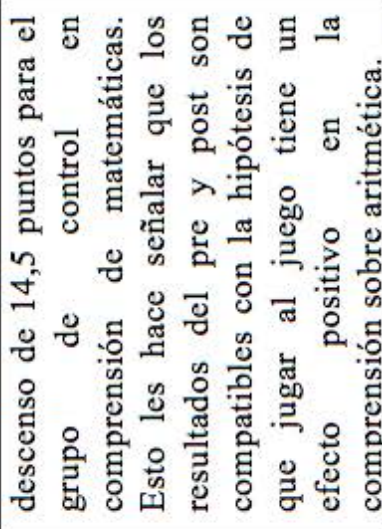 & 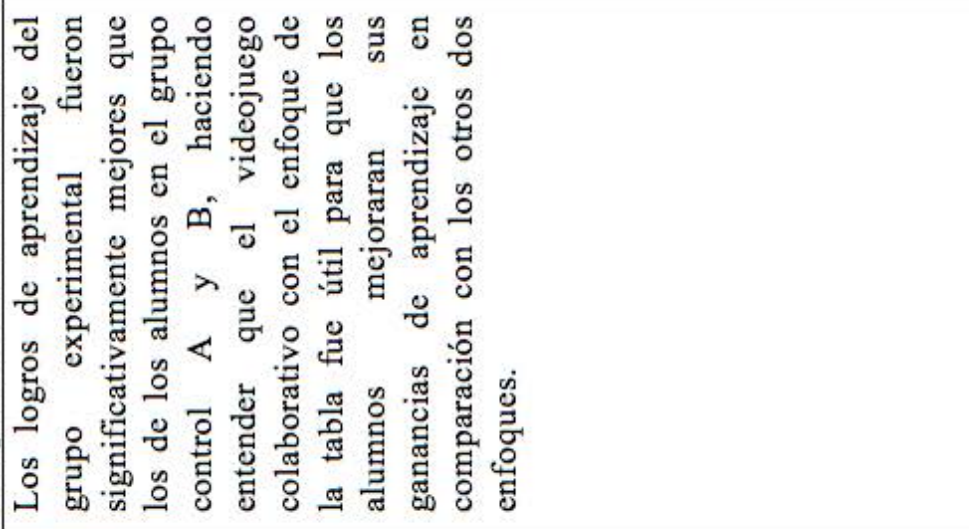 \\
\hline & 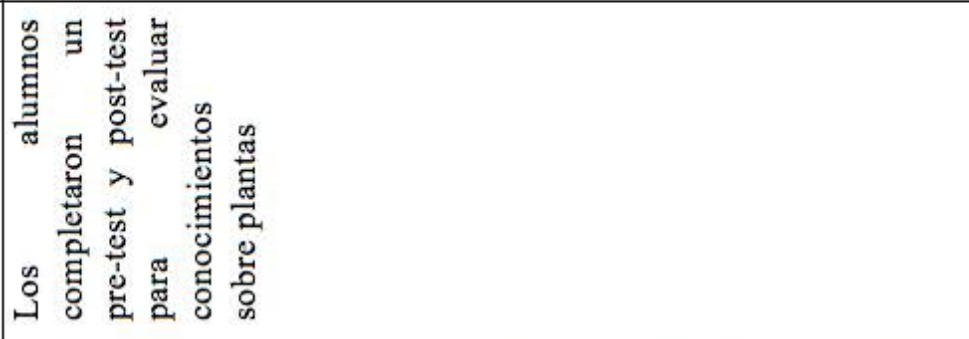 \\
\hline 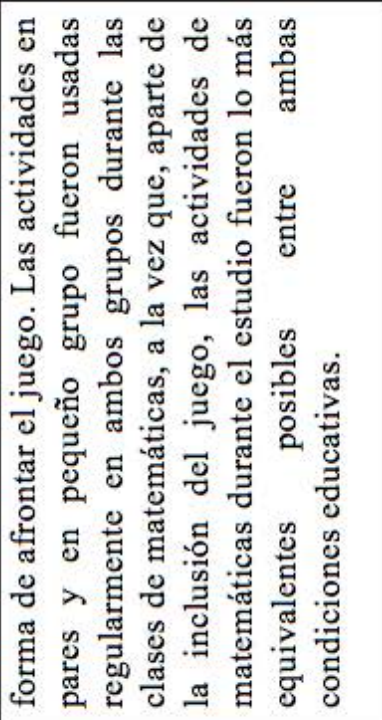 & 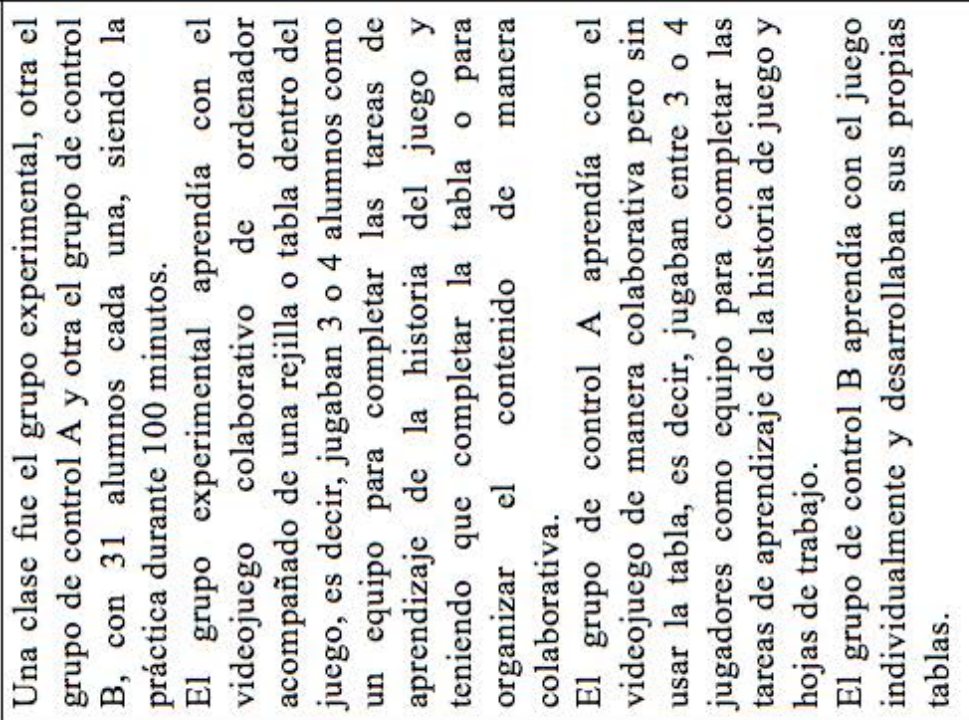 \\
\hline & 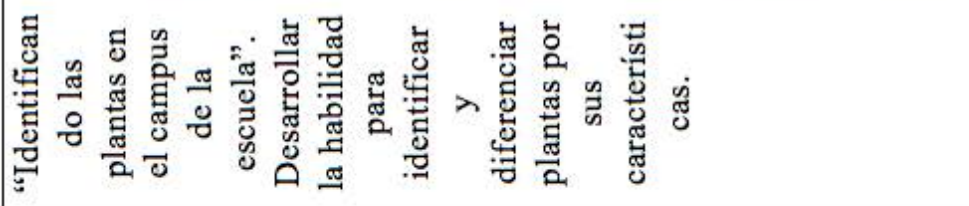 \\
\hline & 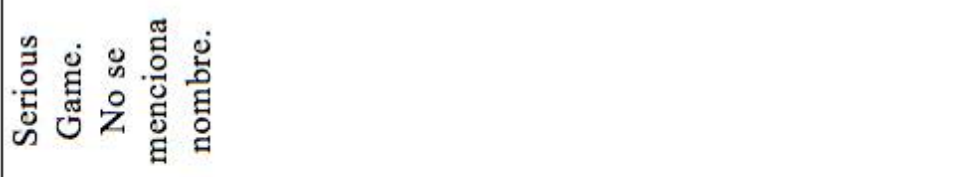 \\
\hline & 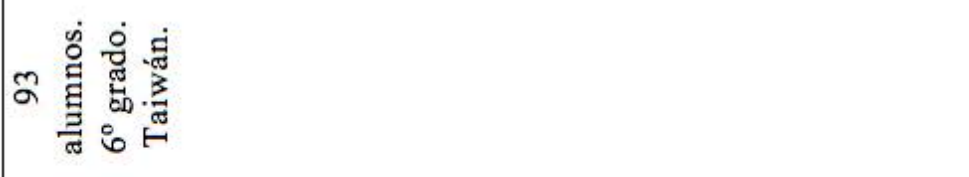 \\
\hline & 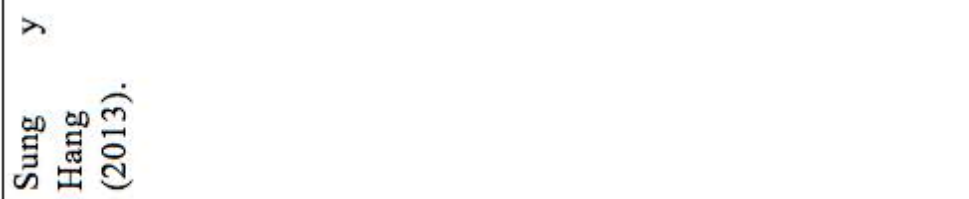 \\
\hline
\end{tabular}




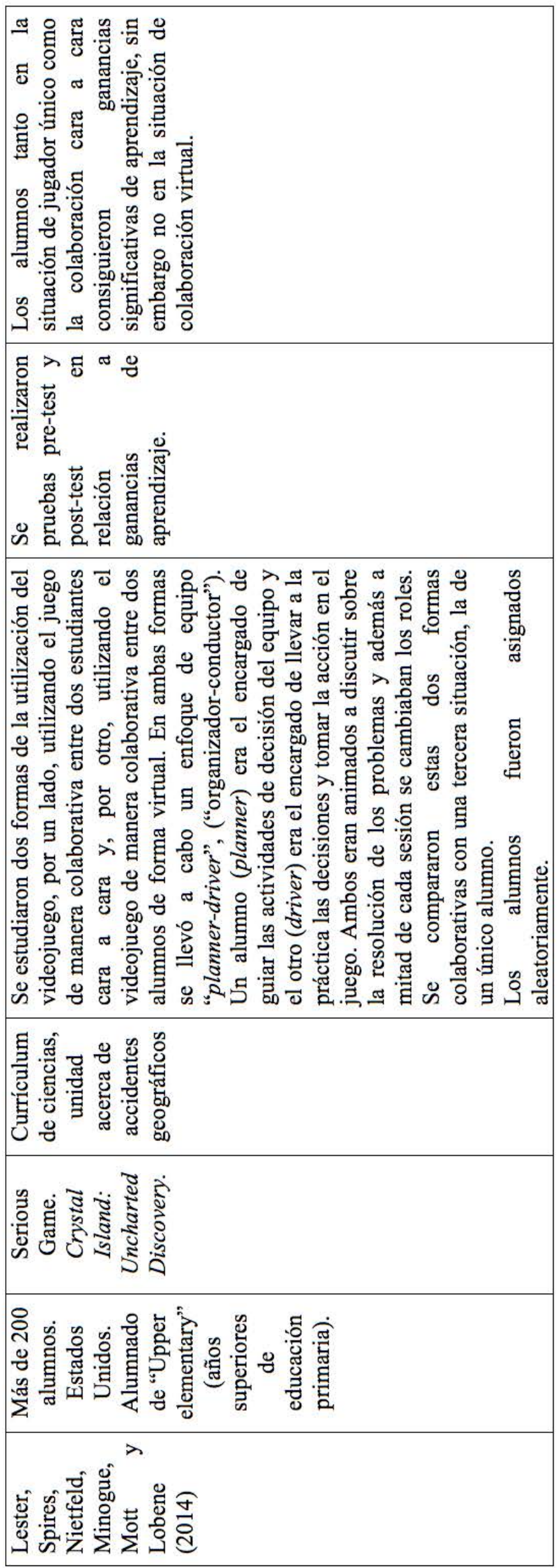




\section{Discusión y Conclusiones}

En términos generales, podemos hablar de un incremento en el aprendizaje del alumnado al realizar prácticas educativas colaborativas en torno a un videojuego, es decir, al realizar actividades educativas en las que el recurso educativo principal es un videojuego y los alumnos han de colaborar ya sea dentro o fuera del videojuego para la realización de actividades de aprendizaje. A su vez, pueden plantearse estas actividades en diversas áreas o para trabajar diferentes contenidos como ciencias, aritmética, geografía y el conocimiento de otras culturas, pareciendo más aplicable en el ámbito de las ciencias como vemos en los estudios. Además, en cuanto al videojuego podemos percibir la utilidad de los Serious Games pues todos los estudios usan esta tipología, lo que nos hace pensar que resulta más fácil de incorporar un videojuego que ya incluye directrices o contenido educativo como los Serious Games, que la aplicación de Games for Entertainment. En cuanto a limitaciones, en primer lugar, los estudios que cumplen con nuestros criterios de demarcación son escasos, sin embargo, consideramos que los criterios señalados nos permiten analizar la situación planteada en nuestro objetivo de estudio. En el proceso de revisión de la literatura, la exclusión de estudios se debió sobre todo al hecho de que no había una prueba pre-test y post-test que nos permitiera con datos establecer si hubo mejoras de aprendizaje, facilitando así saber si este enfoque es positivo para la práctica y aprendizaje de nuestros alumnos. En algunos casos nos encontramos que solamente se realizaba una prueba post-test (impidiéndonos conocer la situación anterior al juego) y en otros casos las valoraciones en torno a un efecto positivo del uso del videojuego en tareas de trabajo colaborativo se debieron a las percepciones de los investigadores. Es importante de todos modos valorar todos los estudios y experiencias sobre videojuegos y aprendizaje colaborativo, sin embargo no cumplen con los criterios establecidos.

En relación con lo anterior, no todos los estudios seleccionados presentan varios grupos para establecer diferencias entre diferentes modos de agrupación o de trabajo del alumnado, lo que permitiría ver si unos métodos son más efectivos que otros. Sería interesante en un futuro la existencia de más estudios en esta línea, aunque conocemos las dificultades, limitaciones y algunos aspectos éticos que podría conllevar.

Por otro lado, se hace difícil comparar los estudios señalados al encontrarnos muestras de muy diferente tamaño (además de algunas muy pequeñas), a la par que diferente organización, modo de agrupación y planteamiento de las actividades de trabajo colaborativo con los videojuegos.

Detodos modos, cabeseñalar que los resultados obtenidos podrían estar influenciados por el hecho de que en las bases de datos y portales 
utilizados para la revisión y selección de estudios no se incluyen todos los tipos de publicaciones que podrían centrarse en el objeto de estudio que abordamos en este artículo, lo que podría provocar el no haber analizado algunos documentos relevantes. En este sentido, hemos utilizado las que de alguna manera resultan fundamentales para el ámbito trabajado, realizando así una búsqueda lo suficientemente exhaustiva para aproximarnos al fenómeno. Sin embargo, otro tipo de fuentes como, por ejemplo, los blogs docentes también han de tenerse en cuenta como fuentes reales de la práctica de aula en los que los docentes incorporan de manera directa lo realizado, siendo una posible línea de investigación a trabajar en posteriores estudios.

\section{Corrientes cognitivistas}

Este trabajo ha sido financiado gracias a (Formación del Profesorado Universitario) del una ayuda predoctoral del Programa FPU Ministerio de Educación, Cultura y Deporte.

\section{Referencias}

AEVI \& GfK (2012a). Estudio Videojuegos, educación y desarrollo infantil. Fase cualitativa. Recuperado el 20 de noviembre de 2014 de http://www.aevi.org.es/index. php?option $=$ com_mtree\&task=att download\&link_id $=55 \&$ cf_id $=30$

AEVI \& GfK (2012b). Estudio Videojuegos, educación y desarrollo infantil. Fase

Cabe finalizar diciendo que hemos podido dar respuesta a nuestra pregunta de investigación, pues podemos señalar que sí pueden plantearse en la etapa de Educación Primaria, es decir, con alumnado de 6 a 12 años, actividades de trabajo colaborativo entre los propios alumnos en las que el recurso principal en torno al que se desarrolla la actividad sea un videojuego, ya sea colaborando dentro del videojuego o fuera de él. A su vez, hemos podido alcanzar los objetivos planteados pues hemos conocido diferentes actividades de aprendizaje colaborativo con videojuegos con alumnado de 6 a 12 años y que en términos generales han mejorado los resultados de aprendizaje del alumnado participante en dicho planteamiento de aula.

\section{Universitario) del}


R. Fernández, M. I. Pedrera, y J. Valverde. Brighter Child Interactive (1996). Message in (Coords.), Actas del II Congreso Internacional a Fossil [videojuego].

de Videojuegos y Educación (pp. 595-624).

España: Bubok Publishing.

Calzadilla, M. E. (2002). Aprendizaje colaborativo y Tecnologías de la Información

Arias, C. y Revuelta, F. I. (2014). Propuestas la Comunicación. OEI-Revista didácticas para la aplicación de videojuegos Iberoamericana de Educación. Recuperado en el aprendizaje de competencias básicas. el 20 de noviembre de 2014 de http://www. En F. I. Revuelta, M. R. Fernández, M. I. Pedrera y J. Valverde. (Coords.) Actas del II Congreso Internacional de Videojuegos y Educación (pp. 503-515). España: Bubok Publishing.

Carrió, M. L. (2007). Ventajas del uso de la tecnología en el aprendizaje colaborativo. Revista Iberoamericana de Educación, 41. Recuperadoel 1 de diciembre de 2014 de http: / /

Ascaron y FX Interactive (2004). Sacred www.rieoei.org/deloslectores/1640Carrio.pdf [videojuego].

Electronic Arts (2005). Harry Potter y el Barkley, E. F., Cross, K. P., \& Major, C. H. Cáliz de Fuego [videojuego]. (2007). Técnicas de aprendizaje colaborativo: Manual para el profesorado universitario. Madrid: Ministerio de Educación y Ciencia y Etxeberría, F. (1998). Videojuegos y educación. Comunicar, 10, 171-180.

Ediciones Morata.

Felicia, P. (2009). Videojuegos en el aula.

Big Blue Box y Microsoft (2004). Fable Manual para docentes. Bruselas: European [videojuego].

Schoolnet. Recuperado el 23 de noviembre de 2014 de http://games.eun.org/upload/GIS

Boland, A., Cherry, M. G. y Dickson, R. HANDBOOK_ES.pdf (2014). Doing a systematic review. A student's guide. California: Sage.

Game Freak y Nintendo (2007). Pokémon Diamante [videojuego].

Bottino, R. M., Ferlino, L., Ott, M. y Tavella, M. (2007) Developing strategic and reasoning abilities with computer games at primary school level. Computers \& Education, 49(4), 1272-1286. http://dx.doi.org/10.1016/j. compedu.2006.02.003

García Gigante, B. (2009). Videojuegos: medio de ocio, cultura popular y recurso didáctico para la enseñanza y aprendizaje de las matemáticas escolares. Tesis Doctoral, Universidad Autónoma de Madrid. 
García, M. F. y Raposo, M. (2013). Trabajando con videojuegos en el aula: Una experiencia con Wii Music. Tendencias Pedagógicas, 22, 45-58. Recuperado el 13 de abril de 2015 de http://www.tendenciaspedagogicas.com/ Articulos/2013_22_05.pdf

García-Valcárcel, A. y Basilotta, V. (2015). Evaluación de una experiencia de aprendizaje colaborativo con TIC desarrollada en un centro de Educación Primaria. Edutec-e. Revista Electrónica de Tecnología Educativa, 51, http://www.edutec.es/revista/index. php/edutec-e/article/view/200/pdf_30

Garibay, G., Vázquez, J. R., Hernández, M. T., Romo, M. E., Castañeda, M., Aceves, M. L. y Martínez, A. (2008). El trabajo colaborativo entre niños de tres primarias mediante foros de discusión en línea. Informe de investigación. Universidad Autónoma de Guadalajara. Recuperado el 16 de abril de 2015 de http://genesis.uag.mx/dapa/doctos/ intelliga.pdf

Garzotto, F. (2007). Investigating the Educational Effectiveness of Multiplayer Online Games for Children. En Proceedings of the 6th international conference on Interaction design and children (pp. 2936). Aalborg, Dinamarca. http://dx.doi. org/10.1145/1297277.1297284

Gee, J. P. (2004). Lo que nos enseñan los videojuegos sobre el aprendizaje y el alfabetismo. Archidona, Málaga: Aljibe.
Gros, B. (2000). La dimensión socioeducativa de los videojuegos. Edutec. Revista Electrónica de Tecnología Educativa, 12. Recuperado el 21 de noviembre de 2014 de http://edutec. rediris.es/Revelec2/Revelec12/gros.html

Grupo F9 (2002). Snoopy. Reforzar la lectura en ciclo inicial. Revista Comunicación y Pedagogía, 181.

Guerra, J. y Revuelta, F. I. (2014). Minecraft como herramienta pedagógica. Propuestas metodológicas de aula. En F. I. Revuelta, M. R. Fernández, M. I. Pedrera, y J. Valverde. (Coords.), Actas del II Congreso Internacional de Videojuegos y Educación (pp. 556-575). España: Bubok Publishing.

Henderson, L., Klemes, J. y Eshet, Y. (2000). Just Playing a Game? Educational Simulation Software and Cognitive Outcomes. Journal of Educational Computing Research, 22(1), 105-129. http://dx.doi.org/10.2190/EPJTAHYQ-1LAJ-U8WK

Heyman, D. (productor) y Newell, M. (director). (2005). Harry Potter y el cáliz de fuego [película]. Reino Unido: Heyday Films. Iborra, A., e Izquierdo, M. (2010). ¿Cómo afrontar la evaluación del aprendizaje colaborativo? Una propuesta valorando el proceso, el contenido y el producto de la actividad grupal. Revista General de Información y Documentación, 20, 221-241. 
Recuperadoel 1 dediciembre de 2014dehttp:// revistas.ucm.es/index.php/RGID/article/ viewFile/RGID1010110221A/9030

Lacasa, P. (2011). Los videojuegos. Aprender en mundos reales y virtuales. Madrid: Morata.

Lester, J. C., Spires, H. A. Nietfeld, J. L., learning - a framework for development Minogue, J., Mott, B. W. y Lobene, E. V. and analysis. In M. Kankaanranta \& P. (2014). Designing game-based learning Neittaanmäki (Eds.), Design and use environments for elementary science of serious games (Vol. 37, pp. 69-82). education: A narrative-centered learning Dordrecht: Springer Netherlands. http:// perspective. Information Sciences, 264, 4-18. dx.doi.org/10.1007/978-1-4020-9496-5_5 http://dx.doi.org/10.1016/j.ins.2013.09.005

Lim, C. P., Nonis, D. y Hedberg, J. (2006). Gaming in a 3D multiuser virtual environment: engaging students in Science lessons. British Journal of Educational Technology, 37 (2), 211-231. http://dx.doi.org/10.1111/j.14678535.2006.00531.x

Macías, G. y Quintero, R. (2011). Los videojuegos como una alternativa para el estudio y desarrollo de la orientación espacial. En M. Marín, G. Fernández, L. J. Blanco y M. M. Palarea (Coord.), Investigación en Educación Matemática XV. España: Sociedad Española de Investigación en Educación Matemática.

Marín, V., Ramírez, A. y Cabero, J. (2010). Los videojuegos en el aula de Primaria. Propuesta de trabajo basada en competencias básicas. Comunicación y pedagogía, 244, 1318.
Marquès Graells, P. (2011) Los videojuegos. Recuperado el 22 de noviembre de 2014 de http://peremarques.pangea.org/videojue. htm

Meyer, B., y Sørensen, B. H. (2009). Designing serious games for computer assisted language Meluso, A., Zheng, M., Spires, H. A. y Lester, J. (2012). Enhancing 5th graders' science content knowledge and self-efficacy through game-based learning. Computers $\&$ Education 59, 497-504. http://dx.doi.org/10.1016/j. compedu.2011.12.019

Mojang (2009). Minecraft [videojuego].

Nintendo (2006). New Super Mario Bros. [videojuego].

Nintendo (2008). Wii Music [videojuego].

Pareto, L., Haake, M., Lindström, P., Sjödén, B., y Gulz, A. (2012). A teachable-agentbased game affording collaboration and competition: evaluating math comprehension and motivation. Educational Technology Research and Development, 60(5), 723-751. http://dx.doi.org/10.1007/s11423-012-92465 
Pedrero, C., Sánchez, M. C. e Iglesias, A. (2014). Percepciones de los docentes de Educación Primaria sobre los procesos curriculares de Aprendizaje Colaborativo con el uso de las TIC. En González, L. M., García-Valcárcel, A., Martín, J., Sousa, J. S., Meirinhos, M. y Gonçalves, V. (Coords.), Aprender, colaborar e innovar a través de las TIC. Ponencias, investigaciones y experiencias educativas presentadas en el III Congreso Ibérico de Innovación en Educación con las TIC. Salamanca: Ediciones Bracamonte.

\section{Real Academia Española (RAE)}

(2001). Colaborar. Recuperado el 22 de noviembre de 2014 de http://lema.rae.es/ drae/?val=colaborar

Renou, C. y Lozano, J. (2010). Aprendizaje colaborativo para acceder a la lengua castellana con alumnado extranjero. En II Jornadas de los Máster en Investigación e Innovación en Educación Infantil y Educación Primaria, pp. 487-515.

Revuelta, F. I. y Guerra, J. (2012). ¿Qué aprendo con videojuegos? Una perspectiva de meta-aprendizaje del videojugador. RED. Revista de Educación a Distancia, 33. Recuperado el 23 de noviembre de 2014 de http://www.um.es/ead/red/33/revuelta.pdf
Santamaría, E. y Grupo F9 (2007). Haunted House. Comunicación y pedagogía, 224, 8386.

Sánchez-Meca, J. (2010). Cómo realizar una revisión sistemática y un meta-análisis. Aula Abierta, 38(2), 53-64. Recuperado el 16 de abril de 2015 de http://www.um.es/ metaanalysis/pdf/5030.pdf

Scagnoli, N. I. (2006). El aprendizaje colaborativo en cursos a distancia. Investigación y Ciencia, 36, 39-47.

SCE Santa Monica Studio, Bluepoint Games y Sony Computer Entertainment (2005). God of War [videojuego].

Sung, H. Y. y Hwang, G. J. (2013). A collaborative game-based learning approach to improving students' learning performance in science courses. Computers $\&$ Education, 63, 43-51. http://dx.doi.org/10.1016/j. compedu.2012.11.019

Tüzün, H., Yilmaz-Soylu, M., Karakus, T., Inal, Y. y Kizilkaya, G. (2009). The effects of computer games on primary school students' achievement and motivation in geography learning. Computers $\&$ Education, 52, 68-77. http://dx.doi.org/10.1016/j. compedu.2008.06.008 